\title{
Research on Construction of the Chinese University Internal Control system
}

\author{
He Fan, Zhu Boyang, Zhao Jie, He Yuequn \\ College of Economics and Management, Southwest University, Chongqing 400700, China \\ zza1800@swu.edu.cn
}

\begin{abstract}
With the deepening of education system and the college expansion plan in China, universities have witnessed great changes in personnel training, capital source, funds management and performance evaluation. However, the current system of internal control in universities fails to match to these new trends which cannot adapt to these new needs of fostering talents, scientific research and serving for society to some extent. Thus, how to improve the theory and practice of the system of internal control in university has become a new hot point for experts at home and abroad.
\end{abstract}

Index Terms - university, internal control, system

\section{Introduction}

Throughout the internal control system of research, the most significant point is undoubtedly the American COSO guidance issued by the Commission "Internal Control Integrated Framework" report. It consists of five related parts, including environment control, risk assessment, control activities, information and communication and monitoring, which has wide influence. Nevertheless, ABS has elaborated in SAS NO.1 that the interior accounting control in universities is composed of school planning, asset protection, financial information truthfully record and so on. In addition, its scope involves teaching, scientific research, infrastructure, daily expenses, tuition income, operating income and other aspects of the funds income. As the spread and influence of the research results above, foreign colleges and universities have begun to attach importance to internal control, and follow the guidance of the theory, to build a line with its own characteristic internal control system.

Compared with the research abroad of interior control, our research started late, and our system was based on weak consciousness of interior control in universities and problems like frequent occurrence of economic cases. To deal with financial frauds in universities, we issued The Financial Regulations of Colleges and Universities in 1997, and in succession, rules such as The Regulations of Interior Accounting in Education System and Several Opinions from Finance Department of Education Ministry on Further Strengthening the Management of University Capital Safety. Currently, Chinese theory scholars' research on internal control research focuses on its target and principles, and never formed a coordinated organic system. Moreover, documents of research on internal control for non-profit organizations are limited, and those research would like to focus on the frame of COSO rather than on these specific features in our universities. Therefore, it is important and meaningful to do further research on system of interior control in universities and put forward construction ideas and improvement measures, so as to improve and ensure the quality of universities' interior control and make it play a better role.

\section{Objectives of Internal Control}

University, as a non-profit organization, has quite large differences with enterprises on its operating content and character. Its target of internal control is essentially different with that of enterprises. Therefore, on the construction of the system of interior control in universities, we should neither blindly copy the goal of COSO report nor hang back and completely imitate what enterprises define for the target of interior control. We should, instead, adjust the target in accordance with the university's function and operation.

Nowadays, as our college's goal is to cultivate individuals, do scientific researches and serve the society, we should not take enterprises as examples, but should base on the realizing of developing talents and serving society. We should build up a perfect system of interior control to make colleges and universities accomplish their teaching work and research activities efficiently and orderly. In this way, those schools can balance school-running funds and ensure capital safety, meanwhile, they can cultivate more talents for society and play their role well to service for scientific research.

\section{The System Construction of Internal Control in Universities}

\section{A. The Frame Structure of Internal Control}

According to the situation of our universities, this thesis will discuss the frame system construction of interior control from seven aspects: control environment, budget management, risk recognition and response, control methods, information and communication, performance evaluation and supervision and feedback. The framework is as below: 


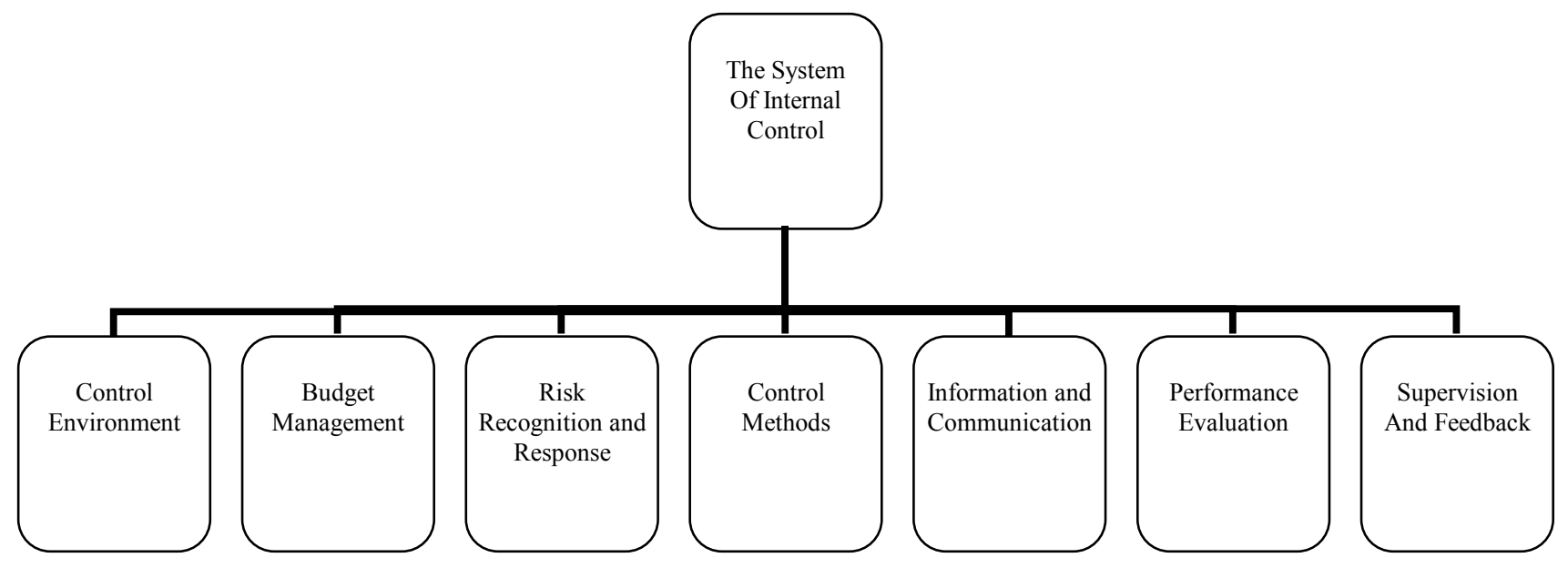

Fig. 1 the system construction of internal control in universities

\section{B. Control Environment}

The key to environment of interior control is to build a reasonable administration structure in universities. The administration system in universities now is headmaster-incharge system with the leadership of the Party committee. The likely problem of this system is as disproportionate administrative power, weak academic strength and ineffective participation in democratic decision-making from teachers and students. Take a general view of western companies' administration practice, it is a more ideal organizing model in modern companies that establishing a board of directors as the highest capability and decision-making mechanism within the company. Therefore, our colleges and universities can take example by some of its methods to form a council by investors, specialists and scholars from every department, social elites without direct interests with university as well as student representatives. The council has the right of making decisions and the proper separation from the administrative system led by the principal. In this way, the university will become an organization which takes responsibility for the public rather than the internal staff. Thus, such governance structure not only ensures university's scientific decisionmaking activities, but also to achieve a balance of power and the promotion of long-term goals of the university.

\section{Budget Management}

Nowadays, our college capital comes from financial allocation and undertaking revenue, the former of which is determined by the budget of university. However, the preparation of the budget in many universities is often the lack of scientific rationality. They merely draw up the budget in the way of zero-base budget, namely, taking last year's budget as the base, then adding up with this year's accrual in capital. The funds resulted from this can only be increased. In addition, one department may have problems with another for fighting for funds. As for the budget management, universities should mark off different objectives based on talents cultivation, scientific research and society service and then break down the objectives with different functions into several sub-goals. Goals at each level all should be based on actual business and service objectives. The budget should be submitted after reasonable calculation to optimize resource allocation. Besides, the budget punishment system should also be consummated. Excess budget from any department without sufficient reason should be punished.

\section{Risk Recognition and Response}

With rapid development of higher education, colleges and universities have embarked on the road of debt management, which led to Chinese colleges and universities facing an unprecedented educational and financial risks. The expansion of enrollment, teaching surge in demand, as well as space and equipment updates necessarily require the introduction of credit funds. Under the new conditions, universities should not be in a circle or loan without plan. Universities should establish a certain risk tolerance and mechanism of risk control. To be specific, firstly, university should judge, assess and evaluate risk and control it by avoiding, limiting, transforming, dispersing and defusing. Secondly, scientific investment decision-making mechanism should be established with the related experts demonstrating the feasibility of the important projects and group decisionmaking.

\section{E. Control Means}

In reality, many universities may not be able to effectively control the assets, and sometimes even produce the phenomenon of loss of assets. Thus, it is key to ensure the security of funds in universities. The means of control can be divided into two parts: the management of organizational level and the management of operational level. In the organizational level, universities should propose centralized control, especially for school-run enterprises and secondary sectors where property rights are not very clear. Thus, important financial activities should be managed by the school. In the operational level, the significant financial activities in campus 
infrastructure sectors, settlement department, back office and research organizations should be into centralized procedures and control. Meanwhile, school should monitor the secondary accounting sectors in materials purchasing, construction work and loan with strict monitoring system and programs. Thus, school can try its utmost best to reduce the loss of university's interests caused by secondary accounting sectors which emphasize the decision-making right but neglect management.

\section{F. Information and Communication}

University accounting information is the main source of its internal information, which is also the intermediary of communication for multi-level governments in university. Thus, it's significant for university to take proper measures to emphasize information exchange. The system of internal control should be improved from such three aspects: firstly, financial staff should be organized at regular intervals to reveal financial data with intensification to make every department can get the information in time. And for the great projects, the information should be reported at any time. Secondly, the system of information exchange should be set up between departments in order to ensure that all work smoothly. Thirdly, university should analyze every item well and create the environment of information sharing, which can eliminate negative effects of not-free information.

\section{G. Performance Evaluation}

The work achievement of researchers and teachers, who are the subjects of colleges and universities, is not only the cornerstone and the driving force to the development of the colleges and universities, but also the key factors of providing technology services to the public and personnel training. At present, teachers' performance primarily is based on their academic achievements, which caused the plagiarism, fraud and so on. Such mode is unfavorable to the long-term development of colleges and universities. As can be seen, only the reasonable evaluation on teachers' performance, and through the evaluation to give appropriate incentives, can be able to encourage the teachers to make more contributions. Therefore, the performance evaluation of colleges and universities should fully consider the teachers' moral level, teaching quality, professional level and other factors. In addition, colleges and universities should also be reasonable allocation of university staff salaries and ensure fair promotion channel, so that it can help to break down the rigid university evaluation mode.

\section{H. Supervision and Feedback}

To monitor and feedback is an important guarantee of implementing and perfecting the interior control. According to the status quo of colleges and universities in our country, college Audit Office acts a significant role to undertake internal control and apply feed back. Auditors, however, of the current higher education carries the work in under the leadership of party committee as the center of administrative management work, the supervision of the independence and authority is easy affected by top leaders. According to this situation, colleges can draw lessons from the practice of enterprise including the audit committee, namely by financial personnel, administrative personnel and project personnel of the audit committee and audit division, while retaining the school and work as the audit committee which consists of institutions. Hence, it enhances the status of organization auditing in universities, strengthens the independence of authority, makes audit supervision work more smooth, powerful, and at the same time to ensure the effective implementation of internal control system and the efficiency of each department.

\section{Conclusion}

Only by establishing the scientific and proper system of interior control in university can aims of fostering talents, scientific research and serving for society be achieved. There exists a lot defects in current system. Thus, the model which is dominated by traditional financial supervising should be improved to integrated management system. Meanwhile, proper and efficient system of interior control should be set up. By this way, the overall management can be improved which can ensure all work smoothly in university.

\section{Reference}

[1] Annukka Jokipi, "Determinants and consequences of internal control in firms," Springer Science and Business Media, vol. 2, no. 3, pp. 1-12, March 2009.

[2] Hammed Arad and Barak Jamshedy-Navid, "A clear look at internal controls: theory and concepts," Social Science Research, vol. 27, no. 7, pp. 158-171, July 2009.

[3] Foh Noreen, "Control self-assessment: a new approach to auditing," Ivey Business Journal ,vol. 65, no. 20, pp. 17-19, September 2000.

[4] Sato Takahiro and Pan Jia, "Comparison of internal control system in Japan and China," International Journal of Business Administration ,vol. 3, no. 1, pp. 64-69, January 2012.

[5] Jeffrey Doyle, "Determinants of weakness in internal control over financial reporting," Journal of Accounting and Economics, vol. 44, no. 2, pp. 193-223, September 2007. 